\title{
Generosidade para com Amigo, Desconhecido e Inimigo: Juízos Morais de Crianças e Adolescentes ${ }^{1}$
}

\author{
Liana Gama do Vale \\ Heloisa Moulin de Alencar \\ Universidade Federal do Espírito Santo
}

\begin{abstract}
RESUMO
Neste estudo, investigamos, em um contexto psicogenético, se crianças e adolescentes, ao julgarem se uma pessoa deve ou não ser generosa para com outra, são influenciados pelo tipo de vínculo (amizade ou inimizade) existente entre essas duas pessoas ou pela ausência de vínculo (desconhecido). Entrevistamos individualmente 30 alunos de uma escola pública de Vitória-ES, nas faixas etárias de 7 , 10 e 13 anos. Utilizamos como instrumento uma história-dilema que trazia uma situação escolar cotidiana em que a generosidade poderia ser manifestada para com um personagem que, inicialmente, foi apresentado como amigo, depois, como desconhecido e, por último, como inimigo. Verificamos que a maioria dos participantes decide pela generosidade nas situações de amizade e ausência de vínculo. Os entrevistados de 7 e 10 anos, contudo, sugerem que a ação generosa para com um amigo deve ser mais intensa do que para com um desconhecido. Na situação de inimizade, a maioria dos participantes das três idades decide pela ausência de generosidade. Diante dos resultados encontrados, podemos afirmar, portanto, que a ausência de vínculo influencia os juízos da maioria dos participantes das duas primeiras faixas etárias. A inimizade, por sua vez, influencia os juízos da maior parte dos entrevistados das três idades pesquisadas
\end{abstract}

Palavras-chave: juízo moral; generosidade; amizade; inimizade; vínculos.

\section{ABSTRACT \\ Generosity Towards a Friend, an Unknown Person and an Enemy: Moral Judgments of Children and Adolescents}

In this case study, we researched, in a psychogenetic context, if children and adolescents, when judging if a person must be generous or not towards another, are influenced by the kind of bond (friendship or enmity) existing between those two people or by an absence of a bond (unknown). We individually interviewed, thirty students (aged 7, 10 and 13) from a public school in Vitória-ES. As an instrument, we administered a story-dilemma that used a daily school situation in which generosity could be manifested towards a character, initially introduced as a friend, as an unknown person and, afterwards, as an enemy. We verified that the majority of the participants make decisions regarding generosity based on friendship and absence of a bond. The 7 and 10 year olds, however, had a more intense generous action towards a friend than that towards an unknown person. In an enmity situation, the majority of the participants in all three age group showed an absence of generosity. In view of the results, we can affirm that the absence of a bond influences the judgment of the majority of participants in the two first age group. Enmity, on the other hand, influences the judgment of most of those interviewed from all three age groups.

Keywords: moral judgment; generosity; friendship; enmity; bonds.

No panorama das pesquisas na área da psicologia da moralidade, há uma predominância do tema da justiça. La Taille, Souza e Vizioli (2004), ao revisarem a literatura de 1930 a 2003 que versa sobre a relação entre ética e educação e temas relacionados, constataram que as demais virtudes e a busca da felicidade, praticamente, não aparecem. A questão da normatividade ainda permanece central nas pesquisas da área. Cabe frisar que tal fato está relacionado à influência dos principais autores desse campo, como Kohlberg (1992) e Piaget (1932/1994), que se dedicaram, predominantemente, à noção de justiça. La Taille (2002), no entanto, questiona a primazia dada a tal tema: "Vale dizer, longe de limitar-se a conflitos, 
deveres e regras prescritivas, a moral pode também tratar da "busca da felicidade"” (p. 29).

Diante desse quadro, ressaltamos a importância de incluir estudos sobre outras virtudes, além da justiça, no panorama das produções científicas sobre a moral. Entre as virtudes, optamos pela generosidade. Mas como podemos definir generosidade? E quais as diferenças entre essa virtude e a justiça, considerada $o$ carro-chefe da moralidade?

Comte-Sponville (1995/1997) define generosidade como a virtude do dom. Para o autor, ser generoso é oferecer ao outro algo que não lhe pertence, mas que lhe falta. A generosidade não corresponde a um direito alheio, pois, quando somos generosos, damos ao outro o que corresponde a uma necessidade singular, e não o que lhe compete de direito (La Taille, 2006a). A justiça, por sua vez, é a única virtude que corresponde ao binômio direito/ deveres: "se é reconhecido a alguém um direito, os outros têm o dever de respeitá-lo" (La Taille, 2000, p. 114). Na justiça, o auto-interesse, ao lado do interesse pelo outro, está sempre presente: "A lei justa é boa para todos, inclusive para a pessoa que exerce a justiça" (La Taille, 2006b, p. 62). Na generosidade, todavia, apenas o interesse pelo outro está em jogo. Nas palavras de La Taille (2006b): “O ato de generosidade favorece quem é por ele contemplado, não quem age de forma generosa" (p. 62).

Comparemos, agora, a generosidade com a solidariedade. Comte-Sponville (1995/1997) afirma que "a solidariedade é demasiado interessada ou demasiado ilusória para ser uma virtude. Nada mais é que egoísmo bem entendido ou generosidade mal entendida" (p.99). O autor ressalta que esse valor parte do princípio do agir para receber ou mesmo para se livrar de uma ação constituída na sociedade como um dever, no sentido de preocupar-se com o bem coletivo e com as agruras que os grandes desastres naturais se abatem sobre determinados indivíduos (como enchentes e terremotos). A presença do auto-interesse é marcante na solidariedade. Colegas de um grupo de trabalho acadêmico, por exemplo, podem ser solidários entre si por interesse próprio. Uma criança pode encobrir uma transgressão do irmão para evitar que este fique de castigo e, assim, ter companhia para brincar. Nessas situações, não há o desprendimento pressuposto moralmente pela generosidade.

Em relação à generosidade, "que a solidariedade pode motivá-la, suscitá-la, reforçá-la, não há dúvida. Mas ela só é verdadeiramente generosa desde que vá além do interesse, ainda que bem compreendido, ainda que partilhado - logo, contanto que vá além da solidariedade!" (Comte-Sponville, 1995/1997, p. 101). Mas até que ponto podemos afirmar que, no ato generoso, não há interesse próprio algum? Ao sermos generosos, recebemos retribuição? Comte-Sponville (1995/1997) questiona: "Como saber se o pouco que damos é generosidade, de fato, ou se é o preço de nosso conforto moral, o precinho de nossa conscienciazinha tranquila?" (p. 103). La Taille (2000) afirma que uma pessoa não se beneficia materialmente ao ser generosa, mas pode experimentar prazer ou felicidade com seu ato. Godbout (1992), ao discorrer sobre o dom, afirma que a retribuição existe, mesmo quando esta não é desejada. Ampliando a definição da palavra e, dessa forma, ultrapassando a circulação material dos objetos ou dos serviços, o autor cita a gratidão e o reconhecimento que o ato suscita como retribuições importantes para os doadores. "Por fim, e estranhamente, a retribuição está frequentemente no próprio dom, na inspiração do artista, na transformação pessoal que experimentam os doadores" (p. 136). Notamos, assim, que a retribuição à generosidade parece ser uma questão de ponto de vista. Ao sermos generosos, podemos receber e, na maioria das vezes, recebemos algum tipo de retorno, que, como vimos, não se aplica necessariamente a algo material. O que há de característico na generosidade é que a retribuição é inesperada, não é exigida, não é garantida quando se dá.

$\mathrm{Na}$ época do Natal, algumas crianças acreditam receber presentes do famoso personagem Papai Noel. Nesse caso, nem o reconhecimento, sugerido por Godbout (1992) como um tipo de retribuição, é esperado pelos verdadeiros autores do ato, já que esse retorno é dirigido a um outro irreal. Para os pais, o que parece contar é o prazer sentido pelos filhos. Mas podemos considerar que há generosidade na família? Comte-Sponville (1995/1997) afirma que o amor basta para explicar o que fazemos por nossos familiares e amigos próximos, pois a felicidade destes é a nossa também. A alegria dos pais é perceber a alegria sentida por seus filhos ao receberem os presentes de Natal, por exemplo. O autor argumenta, no entanto, que, muitas vezes, o desejo dos pais opõe-se ao de seus filhos. $\mathrm{O}$ entusiasmo da criança para brincar pode coincidir com o cansaço de um dia de trabalho do pai. Para Comte-Sponville (1995/1997), é nessas oportunidades que se pode dar provas de generosidade. "É simplificar excessivamente não querer ver nenhuma generosidade possível ou necessária em relação a eles" (p. 102). Todavia, o mesmo autor destaca ainda que "dar, quando se ama, está ao alcance de qualquer um" (p. 107). E quando não se ama? 
Segundo Comte-Sponville (1995/1997), "a generosidade nos convida, na falta de amor, a dar exatamente aos que não amamos, por necessitarem mais ou por estarmos mais bem situados para ajudá-los" (p. 110). Para o autor, o amor não está em nosso poder, mas a generosidade depende da nossa vontade. "Portanto, não se trata de amar, mas de agir como se amássemos" (p. 108). Se dependêssemos apenas do amor para dar a outrem, o que seria dos estranhos ou desconhecidos que carecessem de nossa ajuda?

Godbout (1992) afirma que a possibilidade de dar a estranhos, longe de ser um resíduo das sociedades tradicionais, é um traço moderno. Ressalta que esse dom moderno pode ser encontrado entre pessoas de todos os meios sociais, não apenas sob a forma monetária, mas também sob a forma de tempo, como a escuta, as visitas e o acompanhamento de idosos.

Apresentada a definição de generosidade e discutidas algumas características dessa virtude, respondamos, agora, a seguinte questão: Por que, entre tantas virtudes, elegemos a generosidade? De imediato, podemos destacar que os Parâmetros Curriculares Nacionais (PCNs) (Secretaria de Educação Fundamental do Ministério da Educação e do Desporto, 1997) definem quatro blocos de conteúdo para o ensino da ética: respeito mútuo, justiça, diálogo e solidariedade. É útil saber que o enfoque dado ao tema da solidariedade nesse documento se aproxima da ideia de generosidade, já que, ao discorrerem sobre esse valor, se referem a uma doação ao outro, a uma ajuda desinteressada. A generosidade é mencionada, portanto, como um dos valores relevantes para o ensino das diversas áreas e para o convívio escolar.

Um segundo argumento em favor da relevância de um estudo psicológico da generosidade é a possibilidade dessa virtude desempenhar um papel na construção da moral. La Taille e cols. (1998), a partir da realização de pesquisas sobre as virtudes morais segundo as crianças, constataram que a generosidade já faz parte do universo moral infantil. Os autores verificaram que a maioria das crianças de 6 anos afirma que um personagem que se priva de uma fruta predileta para dá-la ao irmão (generosidade) é moralmente mais admirável do que outro que segue uma regra justa como dividir um pacote de biscoitos destinado a ele e ao irmão. A partir dos resultados encontrados nessas pesquisas, La Taille (2000) destaca: "Vale dizer que podemos levantar a hipótese de que, no caminho para a construção do ideal de justiça, a generosidade ... desempenha um papel" (p. 118).
A essa primeira hipótese, La Taille (2006a) acrescenta uma outra: "a generosidade não somente é virtude presente no início da gênese da moralidade, como é melhor assimilada e, portanto, integrada à consciência moral, do que a justiça nesta mesma fase do desenvolvimento" (p. 16). Para testar a referida hipótese, La Taille (2006a) realizou uma pesquisa com crianças de 6 a 9 anos de idade. $O$ autor solicitou aos participantes que atribuíssem sentimentos a personagens injustos e não generosos. Os resultados mostraram que as crianças de 6 anos, em sua grande maioria, atribuem sentimentos positivos ao personagem que comete uma injustiça, já que ele conquistou o que queria com tal ato. As mesmas crianças, no entanto, atribuem sentimentos negativos ao personagem que falta com a generosidade, concebendo o desconforto experimentado por ele. $\mathrm{O}$ resultado encontrado nos leva a considerar, portanto, que a generosidade ocupa, sim, um lugar diferenciado no universo moral das crianças.

Se a generosidade já faz parte do universo moral infantil, torna-se urgente abrir espaço para a sua expressão e favorecer a sua legitimação. Mas como podemos tornar esse valor sensível ao pensamento de crianças e adolescentes? De quê forma podemos introduzir essa virtude na formação moral dos alunos? De acordo com a perspectiva construtivista, para planejarmos qualquer proposta de educação moral, precisamos conhecer o processo de desenvolvimento dos alunos com os quais pretendemos trabalhar. Nas palavras de Piaget (1930/1996):

Quaisquer que sejam os fins que se proponha alcançar, quaisquer que sejam as técnicas que se decida adotar e quaisquer que sejam os domínios sob os quais se aplique essas técnicas, a questão primordial é a de saber quais são as disponibilidades da criança. Sem uma psicologia precisa das relações das crianças entre si e delas com os adultos, toda discussão sobre os procedimentos de educação moral resulta estéril (p. 2).

Assim, antes de elaborarmos uma proposta de intervenção que aborde a generosidade, precisamos conhecer o desenvolvimento do juízo moral relacionado a essa virtude em crianças e adolescentes. Caso contrário, corremos o risco de propor algo em um momento inoportuno e de forma inadequada. Como temos poucas pesquisas sobre o tema, iniciemos, então, pela base: o estudo da gênese dos juízos de crianças e adolescentes no que diz respeito à manifestação de generosidade para com o outro. Neste trabalho, procuramos averiguar, em um contexto psicogenético, 
se os participantes, ao julgarem se uma pessoa deve ou não ser generosa para com outra, são influenciados pelo tipo de vínculo (amizade ou inimizade) existente entre essas duas pessoas ou pela ausência de vínculo (desconhecido).

\section{MÉTODO}

Participaram deste estudo 30 alunos de uma escola pública do município de Vitória - ES: 10 alunos de 7 anos, 10 de 10 anos e 10 de 13 anos de idade, igualmente divididos quanto ao sexo. Com base nas variáveis mencionadas, os participantes foram selecionados por meio de um sorteio na instituição de ensino. Realizamos entrevistas individuais de acordo com o método clínico proposto por Piaget (1926/s.d.; 1932/1994). Utilizamos como instrumento uma história-dilema que trazia uma situação escolar cotidiana em que a generosidade poderia ser manifestada para com uma pessoa. Inicialmente, essa pessoa foi apresentada como amiga, depois, como desconhecida e, por último, como inimiga. Vale ressaltar que os personagens da história foram descritos com a mesma idade e o mesmo sexo do aluno entrevistado no momento. Eis a história e as perguntas apresentadas aos participantes:

$1^{\text {a }}$ parte: Vitor e Tiago têm sete anos de idade, estudam na mesma escola e são amigos. Um dia, Vitor estava lanchando na hora do recreio e percebeu que Tiago estava com fome. Vitor tinha um pacote com cinco biscoitos, e Tiago não tinha nada para comer. O que você acha que Vitor deveria fazer? Por quê? (Versão feminina: Vanessa e Tatiana)

$2^{\mathrm{a}}$ parte: E se Vitor não conhecesse Tiago? Isto é, se fosse a primeira vez que Vitor tivesse visto Tiago naquela escola? $\mathrm{O}$ que você acha que ele deveria fazer? Por quê?

$3^{\text {a }}$ parte: E se Vitor fosse inimigo de Tiago? Isto é, se Vitor não gostasse de Tiago? O que você acha que ele deveria fazer? Por quê?

Sempre que o participante optava pela generosidade, apresentávamos as seguintes perguntas:

Quantos biscoitos você acha que Vitor deveria oferecer a Tiago? Por quê?

É importante mencionar o cuidado ético e científico que buscamos tomar durante o desenvolvimento de nossa investigação, tendo em vista os conteúdos da Resolução n ${ }^{\circ}$ 196/1996 do Conselho Nacional de Saúde (1996) e da Resolução ${ }^{\circ}$ 016/2000 do Conselho Federal de Psicologia (2000). Priorizamos a análise qualitativa dos dados encontrados e utilizamos, em termos percentuais, uma referência quantitativa, que nos auxiliou na apresentação e discussão dos resultados. Dessa forma, após a leitura dos protocolos das entrevistas, elaboramos categorias detalhadas (microcategorias) para as respostas e justificativas dos participantes. Em seguida, listamos todas as categorias detalhadas e agrupamo-las em categorias resumidas (macrocategorias). Obtivemos, assim, um sistema de categorias resumidas e detalhadas para cada estudo realizado.

Concluída a categorização, inserimos os dados em uma planilha do programa estatístico SPSS for Windows (SPSS Inc., 1999). Como nosso objetivo está relacionado a um interesse psicogenético, cruzamos as categorias resumidas elaboradas com as idades dos participantes da pesquisa. Dessa forma, pudemos verificar com maior clareza as semelhanças e diferenças entre as respostas e as justificativas dos entrevistados de diferentes faixas etárias.

\section{RESULTADOS E DISCUSSÃO}

Apresentaremos e discutiremos os dados referentes às três situações separadamente para, em seguida, compararmos os resultados encontrados e analisarmos se o tipo de vínculo ou a sua ausência influencia os juízos de nossos participantes no que diz respeito à manifestação de generosidade para com o outro.

\section{Situação de amizade}

Quando os personagens da história foram apresentados como amigos, todos os participantes de nosso estudo optaram pela manifestação de generosidade. A intensidade da ação generosa, porém, mostrou-se bastante variada entre as respostas dos entrevistados. Metade dos participantes sugeriu que o personagem em questão deveria ser generoso para com seu amigo realizando uma divisão igual de seu lanche. Considerando que o personagem que precisava tomar a decisão tinha um pacote com cinco biscoitos, os entrevistados apresentaram duas opções para a divisão igual desse lanche. A primeira e mais comum foi a partilha ao meio do quinto biscoito do pacote: "Eu acho que ele deveria ter dado dois biscoitos para ele, ficado com dois e dividido o outro no meio. Daria uma metade para o amigo, e a outra ficaria com ele" (Lucas, $7 ; 10)^{2}$. A segunda opção, menos comum e sugerida apenas pelos participantes de 7 anos, foi excluir, de alguma forma, o quinto biscoito para garantir a divisão igual do lanche: "Eu acho que a Vanessa deveria 
dar dois biscoitos para a Tatiana, ficar com dois e o outro que sobrar dar para outra pessoa" (Maria, 7; 4).

Como pode ser observado na Figura 1, a porcentagem desse tipo de resposta decresce em função da idade: enquanto $70 \%$ dos participantes mais novos sugerem a divisão igual do lanche, apenas $20 \%$ dos entrevistados mais velhos apresentam a mesma sugestão.

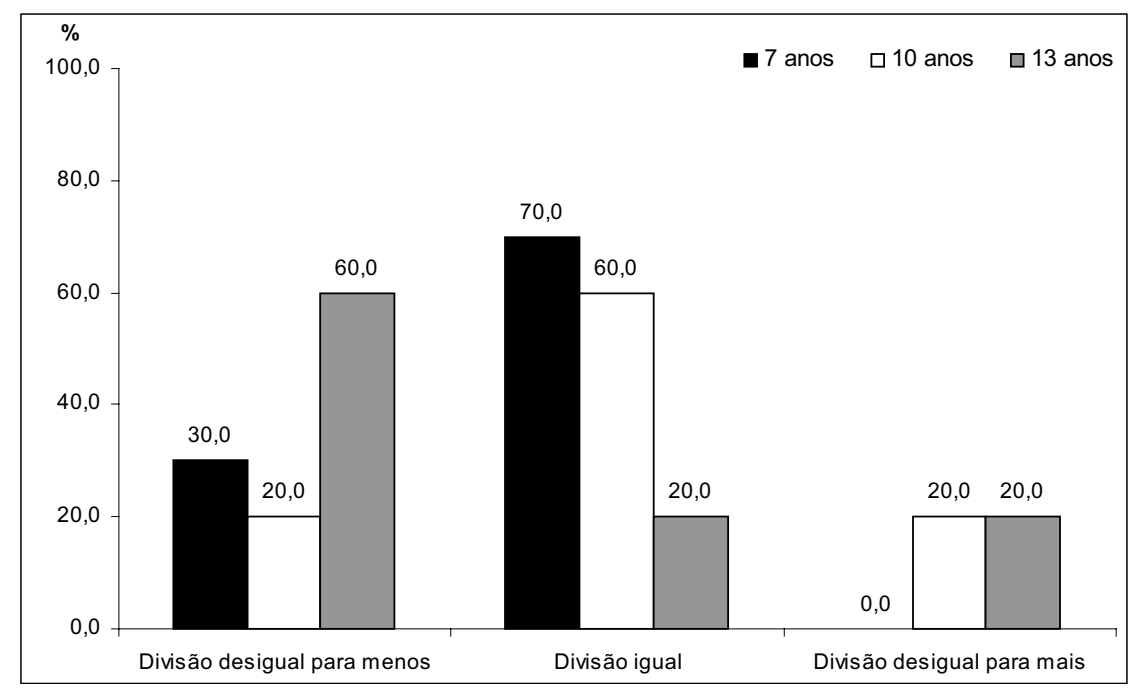

Figura 1. Generosidade para com amigo: comparação das respostas dos participantes conforme a idade.

Uma parte considerável dos entrevistados $(36,7 \%)$ apresentou respostas incluídas na categoria divisão desigual para menos. Aqui, a quantidade de biscoitos que o personagem deveria dar para o amigo era inferior à metade de seu lanche: "Deveria dar dois biscoitos para o amigo dele e ficar com três ..." (Fernando, 7; 11). Como pode ser verificado na Figura 1, há uma predominância da faixa etária de 13 anos nessa categoria. Apenas 13,3\% dos participantes apresentaram respostas da categoria divisão desigual para mais. Nessa categoria, a quantidade de biscoitos sugerida pelos participantes era superior à metade do lanche do personagem: "Daria três para o Tiago e comeria dois" (Fábio, 13; 5). De acordo com a Figura 1, apenas os participantes de 10 e 13 anos apresentaram esse tipo de resposta.

Apreciemos, agora, as razões que os participantes mencionaram para suas decisões na situação de amizade (Tabela 1). Vale destacar que a grande maioria deles apresentou mais de uma razão para cada resposta, por isso o número total de justificativas é superior à quantidade de entrevistados.

TABELA 1

Generosidade Para com Amigo: Distribuição das Justificativas dos Participantes Conforme a Idade

\begin{tabular}{lcccccccc}
\hline \multirow{2}{*}{ Justificativa } & \multicolumn{2}{c}{7 anos } & \multicolumn{2}{c}{10 anos } & \multicolumn{3}{c}{13 anos } & \multicolumn{3}{c}{ Geral } \\
\cline { 2 - 9 } & $\mathbf{N}^{\mathbf{0}}$ & $\%$ & $\mathbf{N}^{\mathbf{0}}$ & $\%$ & $\mathbf{N}^{\mathbf{0}}$ & $\%$ & $\mathbf{N}^{\mathbf{0}}$ & $\%$ \\
\hline $\begin{array}{l}\text { Condições de quem precisava } \\
\text { ajuda }\end{array}$ & 9 & 90,0 & 4 & 40,0 & 9 & 90,0 & 22 & 73,3 \\
$\begin{array}{l}\text { Condições de quem precisava tomar } \\
\text { a decisão }\end{array}$ & 2 & 20 & 1 & 10 & 3 & 30 & 6 & 20 \\
$\begin{array}{l}\text { Reciprocidade } \\
\text { Amizade }\end{array}$ & 0 & 0,0 & 4 & 40,0 & 1 & 10,0 & 5 & 16,7 \\
Justiça baseada na igualdade & 4 & 40,0 & 7 & 70,0 & 5 & 50,0 & 16 & 53,3 \\
Para evitar confusão & 2 & 20,0 & 3 & 30,0 & 0 & 0,0 & 5 & 16,7 \\
Outros & 4 & 40,0 & 0 & 0,0 & 0 & 0,0 & 4 & 13,3 \\
& 0 & 0,0 & 0 & 0,0 & 3 & 30,0 & 3 & 10,0 \\
\hline
\end{tabular}


Como podemos perceber na Tabela 1 , a maior parte dos participantes $(73,3 \%)$ apresentou justificativas que se encontram na categoria condições de quem precisava de ajuda. As condições mencionadas pelos entrevistados, na maioria das vezes, faziam parte do conteúdo da própria história: "Porque ele estava com fome e não tinha nada para comer" (Fernando, 7; 11). Alguns participantes, no entanto, a partir das condições que relatávamos, acrescentavam alguns detalhes ao justificarem suas respostas: "Porque essa criança poderia até passar mal por não ter nada para comer, entendeu?" (Daniel, 13; 9). Conforme podemos verificar na Tabela 1, não encontramos gênese nessa categoria. Há uma predominância desse tipo de justificativa nas faixas etárias de 7 e 13 anos.

As condições de quem precisava tomar a decisão foram mencionadas por $20 \%$ dos participantes para justificar a intensidade da ação generosa para com o amigo: "Porque ele tinha uma quantidade de cinco biscoitos ... . Aí, eu acho que ele poderia dar um, não iria fazer tanta falta para ele" (Márcio, 13; 3).

A reciprocidade foi mencionada por $16,7 \%$ dos entrevistados para justificar a decisão pela generosidade na situação de amizade:

Porque se, um dia, a Tatiana tivesse com biscoito e ela não tivesse com biscoito, a Tatiana daria para ela porque ela deu para a Tatiana. Agora, se ela não desse para a Tatiana, ela ficaria com fome e, aí, a Tatiana não daria para ela quando tivesse biscoito (Marina, 10; 6).

A generosidade expressa por esses participantes parece aproximar-se da definição de solidariedade de Comte-Sponville (1995/1997), já que eles tendem a ajudar o outro para que, em situações análogas, sejam ajudados também. A presença do auto-interesse, característico da solidariedade, é marcante em suas falas.

Como pode ser verificado na Tabela 1 , mais da metade dos participantes $(53,3 \%)$ mencionaram a amizade como motivo para a manifestação de generosidade: "Porque elas eram amigas e, quando a gente precisa, a amiga sempre dá ajuda para a gente" (Letícia, $10 ; 10)$. Ser amigo de uma pessoa implica, então, ajudá-la nos momentos de necessidade? A maioria dos participantes que apresenta justificativas dessa categoria ressalta que esses comportamentos de ajuda fazem parte da relação de amizade sim, e, na maioria das vezes, um gesto de auxílio no momento de necessidade do outro se coloca como condição dessa relação: "Porque, como elas são amigas, tem que ajudar uma a outra, não é? Se ela não ajudasse, por exemplo, ela não estaria sendo amigável com ela" (Eliza, 10; 9).

Mas podemos considerar moral uma decisão pela ação generosa justificada pelo sentimento de amizade existente entre os personagens? A princípio, parece-nos válido responder que não, já que tal decisão é tomada na dependência de um sentimento pessoal. Quem nos garante que, na ausência desse tipo de vínculo, a opção pela generosidade seria mantida por tais participantes? É o que veremos ao discutirmos os resultados das duas situações seguintes: generosidade para com um desconhecido e generosidade para com um inimigo. Mas, no momento, discutamos as demais categorias de justificativa referentes à situação de amizade.

De acordo com a Tabela 1, 16,7\% dos participantes apresentaram justificativas da categoria justiça baseada na igualdade. Nessa categoria, como seu próprio nome indica, incluímos as razões que os entrevistados apresentaram para a opção pela divisão igual do lanche. Como exemplo, citamos uma das justificativas mencionadas por Lucas $(7 ; 10)$ : "Porque, aí, iria ficar igual. Um iria comer uma quantidade, e o outro iria comer a mesma. Aí iria ficar justo." Para discutirmos esse dado, voltemos aos resultados referentes às respostas de nossos participantes na situação de amizade.

Vimos que a maioria dos entrevistados das duas primeiras faixas etárias pesquisadas optou pela divisão igual do lanche, enquanto a maior parte dos participantes mais velhos de nosso estudo decidiu pela divisão desigual para menos do lanche. Poderíamos alegar, aqui, que a primeira opção aponta para a virtude justiça? Se a resposta for afirmativa, poderíamos, então, considerar, a partir de nossos resultados, que a maior parte das crianças de 7 e 10 anos, diante da oportunidade de manifestar a generosidade para com um amigo, apresentam decisões inspiradas pela justiça.

Embora tenhamos obtido uma porcentagem baixa da categoria justiça baseada na igualdade, esse tipo de justificativa parece contribuir para nossas indagações. Como pode ser observado na Tabela 1, apenas os participantes de 7 e 10 anos justificaram suas respostas dessa forma. Mas, de acordo com a história que contamos, o personagem que precisava tomar a decisão estava diante de uma oportunidade de manifestar a generosidade ou a justiça?

Relatamos anteriormente que a generosidade consiste em dar a outrem o que lhe falta, mas, que tal fato não corresponde a um direito alheio (La Taille, 2006b). Vimos, também, que a justiça, por sua vez, 
corresponde ao binômio direito/ deveres (La Taille, 2000). Recordadas as definições das referidas virtudes, pensemos no conteúdo da história apresentada aos participantes.

Podemos considerar que uma criança que se encontra com fome e sem nada para comer tem o direito de receber biscoitos de seu amigo? Dito de outra maneira: podemos considerar que uma criança que tem um pacote de biscoitos tem o dever de dividi-lo com seu amigo que se encontra com fome e sem nada para comer? Parece-nos válido responder que não. No entanto, é útil saber que uma pessoa generosa pode ser movida por um sentimento pessoal de dever e, dessa forma, colocar a manifestação de generosidade para com um amigo como uma obrigação, conforme demonstra uma participante (Marina, 10; 6): "Porque tem que dar para as amigas". Todavia, de acordo com La Taille (2000), "tal dever não é derivado de um direito alheio, mas sim do valor moral da virtude em questão" (p. 115). E, nesse caso, não se trata da virtude justiça, ressaltada nas justificativas de alguns participantes de 7 e 10 anos.

Mas por que os participantes que mencionaram a justiça como justificativa basearam esse valor na igualdade? A teoria de Piaget (1932/1994) nos traz contribuições. Conforme vimos anteriormente, o autor, ao estudar o juízo moral na infância, dedicou-se, predominantemente, à noção de justiça. Ao descrever o desenvolvimento da justiça distributiva na criança, ressalta que, no período compreendido entre 8 e 11 anos, aproximadamente, a igualdade prevalece sobre qualquer outra preocupação. Tal consideração parece explicar o aparecimento da justificativa justiça baseada na igualdade na faixa etária de 10 anos. Mas como podemos interpretar a presença da mesma justificativa na faixa de idade de 7 anos? De acordo com o mesmo autor, a igualdade já constitui uma necessidade para crianças dessa idade, desde que não haja conflito com uma figura de autoridade. Ora, esse parece ser o caso da história que contamos aos nossos participantes.

Uma pequena porcentagem $(13,3 \%)$ dos entrevistados apresentou justificativas da categoria para evitar confusão ao sugerir a divisão igual do lanche para com o amigo: "Porque senão uma vai ficar com mais, e a outra, com menos. Aí, iria dar confusão porque a outra iria querer mais. Iria dar confusão" (Maria, 7; 4). A possibilidade de ocorrer uma "confusão" caso a divisão do lanche não fosse realizada de forma igualitária pressupõe uma certa reivindicação por parte do amigo que estava com fome. Este, na opinião de alguns entrevistados, não só exigiria a divisão do lanche, mas também a partilha igual do pacote de biscoitos. De acordo com La Taille (2006a), "ninguém pode, com legitimidade, exigir ser tratado de forma generosa, somente pode desejá-lo" (p. 10). Segundo o mesmo autor, a justiça, sim, pode ser objeto de reivindicação pessoal. Portanto, aqui, mais uma vez, há uma categoria que parece apontar para a virtude justiça. De acordo com os dados apresentados na Tabela 1, apenas os entrevistados de 7 anos ( $40 \%$ deles) mencionaram esse tipo de justificativa.

\section{Situação de ausência de vínculo (desconhecido)}

A maior parte de nossos entrevistados $(73,3 \%)$ optou pela manifestação de generosidade para com o desconhecido. Como na situação anterior, a intensidade da ação generosa variou bastante entre as respostas dos participantes. A maioria dos entrevistados $(43,3 \%)$ apresentou respostas da categoria divisão desigual para menos. Vale ressaltar que alguns participantes, embora tenham sugerido que o personagem deveria dar uma quantidade inferior à metade de seu lanche para o desconhecido, mencionaram a possibilidade de esse personagem tornar-se seu amigo e, assim, aumentar a intensidade da ação generosa para com ele:

Se fosse eu, eu teria dado um. Ela deveria ir lá, entregar o biscoito para ela, perguntar se ela queria, aí, tentaria puxar papo. Se a outra conversasse também, elas começariam a conversar. Poderia surgir uma amizade entre elas aí. Se fosse um papo legal, se ela estivesse gostando e tudo, ela poderia dar mais (Tatiana, 13; 7).

Conforme mostramos na Figura 2, nessa categoria encontramos uma evolução das respostas em função da idade, com uma prevalência da maior faixa etária de nosso estudo. Esta, por sua vez, inexiste na categoria divisão igual, cuja porcentagem é de $30 \%$ nas faixas de idade de 7 e 10 anos.

A ausência de generosidade para com o desconhecido é sugerida por $26,7 \%$ dos entrevistados: "Aí, ele não daria. Deveria sair de perto" (Tadeu, 10; 6). De acordo com a Figura 2, a porcentagem referente a essa resposta é mais acentuada nas idades de 7 e 13 anos, não apontando, portanto, para uma gênese dessa categoria. 


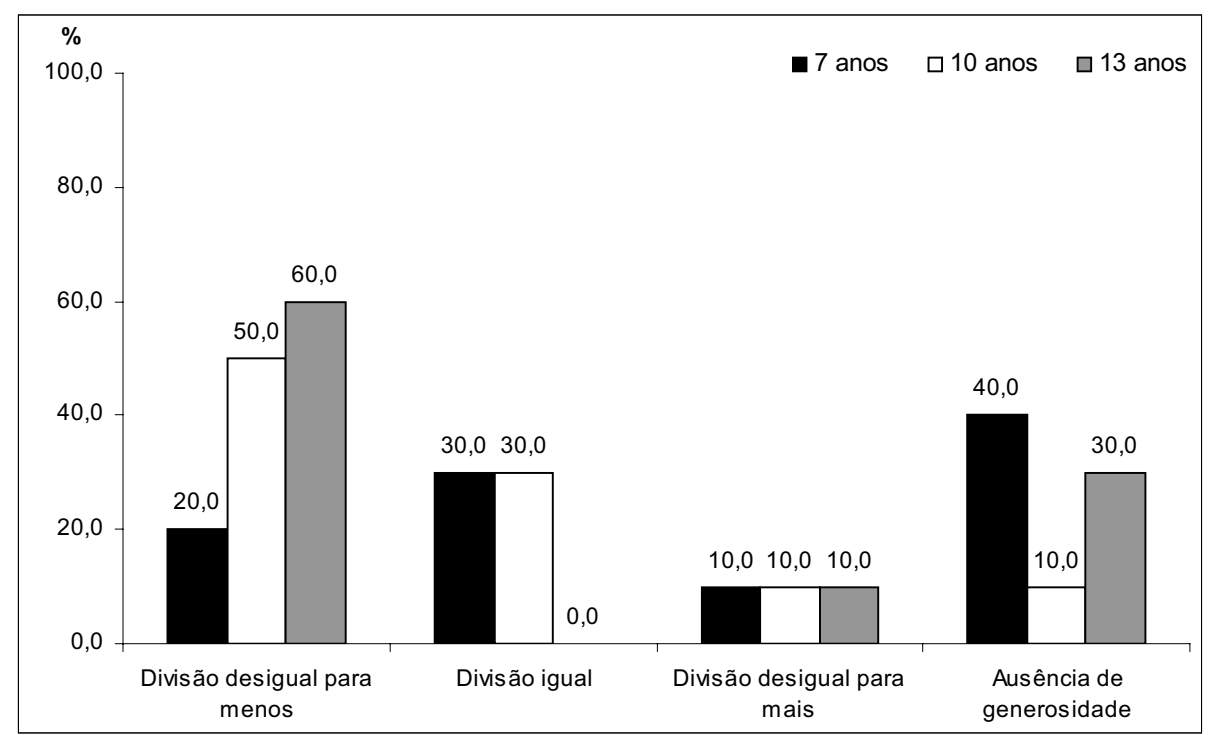

Figura 2. Generosidade para com desconhecido: comparação das respostas dos participantes conforme a idade.

Passemos, agora, para as justificativas apresentadas para tais respostas (Tabela 2). Aqui, novamente, nossos participantes apontaram mais de uma razão para suas decisões.

TABELA 2

Generosidade Para com Desconhecido: Distribuição das Justificativas dos Participantes Conforme a Idade

\begin{tabular}{lcccccccc}
\hline \multirow{2}{*}{ Justificativa } & \multicolumn{2}{c}{7 anos } & \multicolumn{1}{c}{ 10 anos } & \multicolumn{1}{c}{ 13 anos } & \multicolumn{3}{c}{ Geral } \\
\cline { 2 - 9 } & $\mathbf{N}^{\mathbf{0}}$ & $\%$ & $\mathbf{N}^{\mathbf{0}}$ & $\%$ & $\mathbf{N}^{\mathbf{0}}$ & $\%$ & $\mathbf{N}^{\mathbf{0}}$ & $\%$ \\
\hline Condições de quem precisava de ajuda & 4 & 40,0 & 7 & 70,0 & 3 & 30,0 & 14 & 46,7 \\
Reciprocidade & 1 & 10,0 & 3 & 30,0 & 3 & 30,0 & 7 & 23,3 \\
Amizade & 2 & 20,0 & 3 & 30,0 & 2 & 20,0 & 7 & 23,3 \\
Ausência de vínculo & 5 & 50,0 & 5 & 50,0 & 5 & 50,0 & 15 & 50,0 \\
Outros & 4 & 40,0 & 4 & 40,0 & 2 & 20,0 & 10 & 33,3 \\
\hline
\end{tabular}

Conforme dados apresentados na Tabela 2, justificativas das categorias condições de quem precisava de ajuda e reciprocidade continuam sendo apresentadas pelos participantes na situação de ausência de vínculo. A primeira foi mencionada por quase metade dos entrevistados (46,7\%), e a segunda, por $23,3 \%$. Uma outra categoria de justificativa comum à situação anterior é a amizade, ressaltada por $23,3 \%$ dos participantes (Tabela 2). Aqui, no entanto, esse vínculo é mencionado como uma possível consequência da manifestação de generosidade: "Para ele poder ser seu amigo" (Fábio, 13; 5). Percebemos, então, que tais participantes decidem pela ação generosa considerando a consequência do ato. Mas será que poderíamos falar de generosidade nesses casos? Parece-nos lícito responder que não, já que a finalidade dessa ação não é favorecer quem é por ela contemplado, mas satisfa- zer um interesse próprio: fazer uma nova amizade. Ora, sabemos que, na generosidade, apenas o interesse pelo outro está em jogo (La Taille, 2006a).

A ausência de vínculo foi a categoria de justificativa mais comum na presente situação. Vale lembrar que esta foi utilizada tanto para justificar a ausência de generosidade quanto para explicar a intensidade da ação generosa. Como exemplo, citamos a fala de Leandro (7; 9): "Porque ele não conhecia o Tiago. Porque ele não sabia quem ele era nem o nome." Alguns participantes mencionaram, ainda, os possíveis riscos de se manifestar a generosidade para com um desconhecido: "você não sabe como ele vai reagir, se ele vai pegar da sua mão antes de você dar a ele, você não sabe qual vai ser a reação dele ... . Não se julga o livro pela capa" (João, 10; 4). 
Vale destacar, ainda, a alta porcentagem de justificativas da categoria outros na situação de ausência de vínculo. Nessa categoria, incluímos as justificativas que não poderiam ser introduzidas nas categorias citadas anteriormente, nem apareceram com uma frequência suficiente para abrirmos uma nova categoria. É útil saber que a maior parte dessas justificativas foram adicionais, ou seja, correspondiam a uma segunda ou até mesmo terceira razão apresentada pelos participantes para suas respostas. Destaquemos algumas delas.

Um participante de 7 anos disse que o personagem deveria dividir o lanche de forma igualitária para evitar confusão com o desconhecido, justificativa também presente nessa faixa etária na situação anterior. A justiça baseada na igualdade também foi uma justificativa comum à primeira situação, apresentada aqui por dois participantes, um de 7 anos e outro de 10 anos de idade. A preocupação com o juízo alheio foi demonstrada por um participante de 10 anos: "Para mostrar que ele é um menino bom" (Evandro, 10; 7).

De acordo com a distribuição dos resultados apresentada na Tabela 2, não encontramos uma gênese clara nas categorias de justificativa da situação de ausência de vínculo.

\section{Situação de inimizade}

A maior parte de nossos entrevistados (73,3\%) optou pela ausência de generosidade para com o inimigo. Vejamos algumas respostas dessa categoria. Dois participantes mencionaram a possibilidade de optarem pela generosidade, caso o personagem conseguisse voltar a ser amigo do outro, mas deixaram claro que manteriam a opção pela ausência dessa virtude, se tal fato não acontecesse: "Ele deveria tentar ser amigo do Tiago. Se eles resolvessem o problema de serem inimigos, eles seriam amigos. Deveria tentar ser amigo do Tiago e dividir o lanche. ... se eles fossem inimigos, o Vitor não deveria dar lanche" (José, 7; 2).

Uma participante julgou que o personagem não deveria ser generoso para com o inimigo, mas ressaltou um certo cuidado que aquele deveria ter com este:

Acho que ela não deveria dar. Ela deveria, pelo menos, sair de perto dela porque senão a menina vai ficar babando e vai querer o biscoito, entendeu? Vai ficar com mais vontade de comer o biscoito. Ela deveria sair de perto para ela não ficar olhando o tempo inteiro (Marina, 10; 6).

Um outro participante, por sua vez, além da ausência de generosidade, sugeriu uma espécie de provocação do personagem ao seu inimigo: "Não dar, ficar comendo na cara dele" (Tadeu, 10;6). Lucas $(7 ; 10)$ apresentou, ainda, uma outra sugestão:

...ele deveria não ter dado nada ou, então, ele deveria ir lá, escondido, colocar um pouquinho de terra e dar para ele. ... aí, ele poderia ter falado "fui eu que fiz isso" e sair correndo. Ele poderia dar o biscoito e, quando ele comesse, sairia correndo e rindo dele.

Como podemos observar na Figura 3, há uma predominância da ausência de generosidade nas faixas etárias de 7 e 13 anos e uma diminuição dessa opção na idade intermediária de nosso estudo. Não encontramos, portanto, uma gênese dessa categoria.

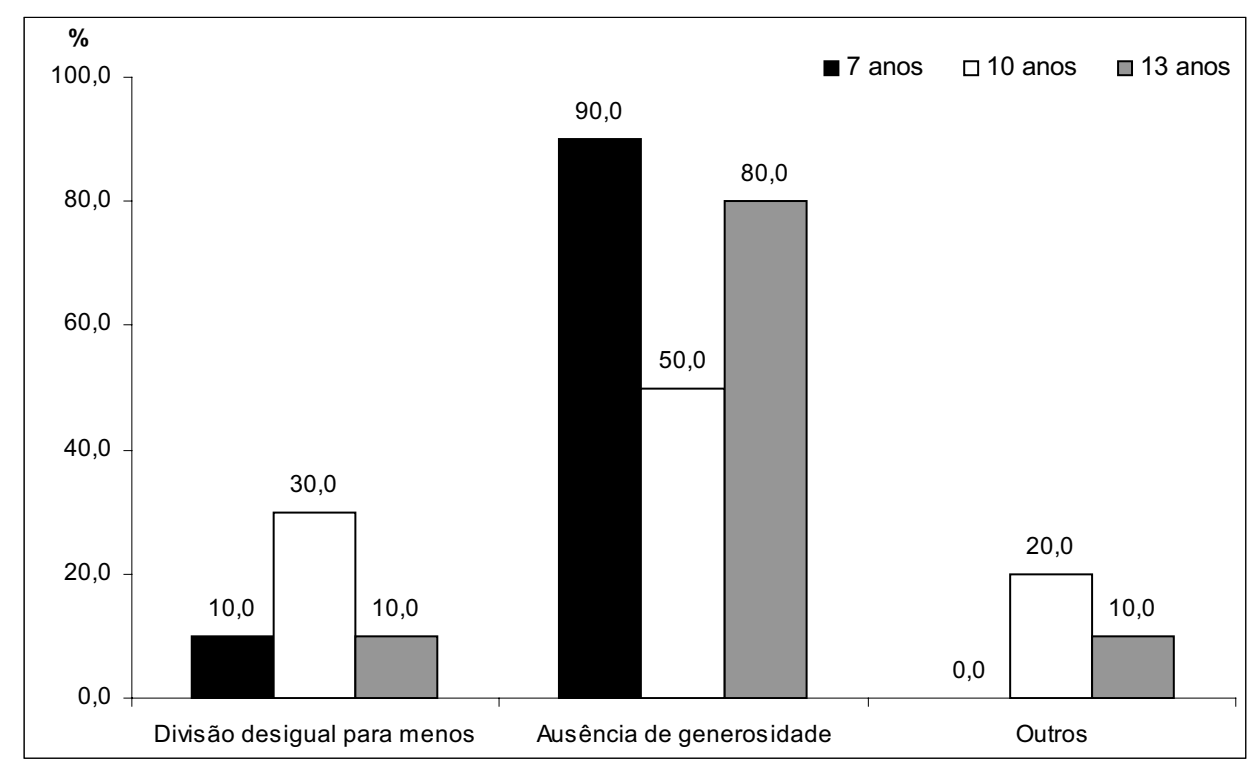

Figura 3. Generosidade para com inimigo: comparação das respostas dos participantes conforme a idade. 
Apenas $16,7 \%$ dos participantes optaram pela generosidade sugerindo uma divisão desigual para menos do lanche. De acordo com a Figura 3, enquanto $30 \%$ dos participantes de 10 anos apresentaram esse tipo de resposta, apenas $10 \%$ dos entrevistados de 7 e 13 anos tomaram a mesma decisão.

Passemos às categorias de justificativa apresentadas na Tabela 3. Aqui, também encontramos mais de uma justificativa por participante. Das categorias apresentadas na Tabela 3, destacamos a inimizade, justificativa mais comum nesta situação. Vale lembrar que esta foi utilizada tanto para justificar a ausência de generosidade quanto para explicar a intensidade da ação generosa. Como exemplo, citamos a justificativa mencionada por Lorena $(10 ; 3)$ : "Porque a Vanessa era inimiga da Tatiana." Alguns participantes ressaltaram, ainda, características desse tipo de vínculo: "Porque, por eles não serem tão ligados um ao outro, não iria haver aquela relação de cooperação. Porque um inimigo não gosta do outro ..." (João, 10; 4).

TABELA 3

Generosidade Para com Inimigo: Distribuição das Justificativas dos Participantes Conforme a Idade

\begin{tabular}{lcccccccc}
\hline \multirow{2}{*}{ Justificativa } & \multicolumn{2}{c}{$\mathbf{7}$ anos } & \multicolumn{2}{c}{ 10 anos } & \multicolumn{3}{c}{ 13 anos } & \multicolumn{3}{c}{ Geral } \\
\cline { 2 - 9 } & $\mathbf{N}^{\mathbf{0}}$ & $\%$ & $\mathbf{N}^{\mathbf{0}}$ & $\%$ & $\mathbf{N}^{\mathbf{0}}$ & $\%$ & $\mathbf{N}^{\mathbf{0}}$ & $\%$ \\
\hline Condições de quem precisava de ajuda & 0 & 0,0 & 2 & 20,0 & 1 & 10,0 & 3 & 10,0 \\
Reciprocidade & 0 & 0,0 & 2 & 20,0 & 1 & 10,0 & 3 & 10,0 \\
Inimizade & 9 & 90,0 & 6 & 60,0 & 8 & 80,0 & 23 & 76,7 \\
Outros & 2 & 20,0 & 3 & 30,0 & 2 & 20,0 & 7 & 23,3 \\
\hline
\end{tabular}

Comparemos, finalmente, os resultados encontrados nas situações de amizade, inimizade e ausência de vínculo.

\section{Comparação dos resultados encontrados nas três situações}

Comecemos pelas respostas apresentadas pelos participantes nas três situações. Notamos que a categoria de resposta predominante na situação de amizade é a divisão igual, sugerida por metade de nossos entrevistados. Na ausência de vínculo, porém, a maior parte dos participantes $(43,3 \%)$ apresentou respostas da categoria divisão desigual para menos. E, na situação de inimizade, a ausência de generosidade prevaleceu, já que foi indicada por $73,3 \%$ dos entrevistados. É interessante ressaltar ainda que a categoria preponderante na situação de inimizade inexiste na situação de amizade, assim como a resposta mais comum na situação de amizade é apresentada por apenas dois participantes na situação de inimizade.

Diante de tal comparação, fica claro, portanto, que o tipo de vínculo ou a sua ausência influencia os juízos da maior parte de nossos participantes no que diz respeito à manifestação de generosidade para com o outro. A maioria deles decide pela ação generosa quando os personagens são apresentados como amigos e quando os mesmos são apresentados como desconhecidos. A intensidade dessa ação, contudo, varia: um amigo, na opinião da grande maioria, deve receber mais lanche do que um desconhecido. Na situação de inimizade, nem mesmo uma ação generosa com intensidade mínima prevalece entre as respostas dos entrevistados, já que a maior parte deles decide pela ausência da virtude. Apenas $10 \%$ dos participantes não alteraram suas respostas em função do tipo de vínculo ou da sua ausência entre os personagens.

Comparemos, agora, os resultados das três situações em função da idade dos participantes, já que nosso objetivo está relacionado a um interesse psicogenético. Na situação de amizade, a maior parte dos participantes de 7 e 10 anos optou pela divisão igual do lanche. Na faixa etária de 13 anos, porém, predomina a categoria divisão desigual para menos. Os participantes das duas primeiras faixas de idade sugerem, portanto, uma ação generosa mais intensa para com o amigo do que os participantes mais velhos do estudo. Conforme comentamos anteriormente, é possível que, na situação de amizade, a decisão dos mais novos seja inspirada pela justiça. Ao analisarmos as razões de todos os participantes de 7 e 10 anos que apresentaram esse tipo de resposta, verificamos que a maioria dos entrevistados de 7 anos e a metade dos de 10 anos mencionaram justificativas da categoria justiça baseada na igualdade. Nenhum participante de 13 anos, por sua vez, apresentou esse tipo de justificativa.

Quando os personagens da história são apresentados como desconhecidos, a categoria de resposta predominante nas duas primeiras faixas etárias não é a 
mesma da situação de amizade. A divisão igual do lanche foi sugerida por apenas $30 \%$ dos participantes de 7 e 10 anos de idade quando os personagens da história foram apresentados como desconhecidos. Nessa situação, a categoria predominante entre as respostas dos participantes de 7 anos foi a ausência de generosidade, e a opção mais comum na faixa de idade de 10 anos foi a divisão desigual para menos. $\mathrm{Na}$ faixa etária de 13 anos, todavia, a categoria predominante, divisão desigual para menos, é a mesma da situação anterior, quando os personagens foram apresentados como amigos. Tal fato demonstra que a ausência de vínculo influencia os juízos da maioria dos entrevistados das duas primeiras faixas de idade pesquisadas, mas que o mesmo não acontece com a maior parte de nossos participantes mais velhos.

La Taille e cols. (1998), ao pesquisarem o lugar da generosidade no universo moral de crianças de 6 a 12 anos, apresentaram, entre outras histórias, duas situações aos participantes: na primeira, um personagem manifestava a generosidade para com um desconhecido e, na segunda, um outro personagem era generoso para com seu amigo. Cabia aos participantes dessa pesquisa decidir qual dos dois personagens citados agiu melhor. De acordo com os autores, a porcentagem de entrevistados que considera melhor a ação generosa para com um desconhecido aumenta em função da idade: enquanto $53,3 \%$ dos participantes de 12 anos indicam o personagem que manifestou a generosidade para com o desconhecido, $31 \%$ dos entrevistados de 9 anos apresentam a mesma resposta e apenas $16,7 \%$ das crianças de 7 anos fazem a mesma opção. Ao perguntarem aos mesmos participantes qual dos dois personagens em questão foi mais generoso, verificaram que a gênese das respostas se torna ainda mais clara: $66,7 \%$ dos participantes de 12 anos, $55,2 \%$ dos entrevistados de 9 anos e $26,7 \%$ das crianças de 7 anos optam pela ação generosa para com o desconhecido. Se os participantes mais velhos tendem a admirar mais a ação generosa para com um desconhecido, está aí uma possível explicação para o fato de a maioria dos entrevistados da maior faixa etária de nosso estudo terem respondido que o personagem da história que contamos deveria realizar a ação generosa para com o desconhecido com a mesma intensidade da ação dirigida ao amigo. Na situação de inimizade, a ausência de generosidade é a resposta mais comum em todas as faixas etárias estudadas, o que indica que esse tipo de vínculo influencia os juízos dos participantes, inclusive os dos mais velhos.
Comparemos, agora, algumas categorias de justificativa apresentadas pelos entrevistados nas diferentes situações. Vimos que as condições de quem precisava de ajuda foram mencionadas pelos participantes nas três situações para justificar a opção pela generosidade. Notamos, no entanto, que essa justificativa foi apresentada por $73,3 \%$ dos participantes, na situação de amizade; por $46,7 \%$ dos entrevistados, na ausência de vínculo; e por apenas $10 \%$ destes, na situação de inimizade. Grande parte dos participantes parece, então, comover-se com as condições em que o personagem que carecia de ajuda se encontra quando este é apresentado como amigo e, até mesmo, como desconhecido, mas as mesmas condições não parecem afetá-los quando se trata de um inimigo.

A amizade foi a segunda categoria mais comum na primeira situação, abarcando $53,3 \%$ das justificativas apresentadas. A ausência de vínculo foi mencionada por metade dos participantes na segunda situação, preponderando sobre as demais justificativas. E a inimizade foi a categoria predominante na terceira situação, abarcando $76,7 \%$ das justificativas citadas. Acreditamos que a alta porcentagem de categorias referentes ao tipo de vínculo ou à sua ausência entre os personagens nas três situações só corrobora a conclusão a que chegamos com os resultados referentes às respostas de nossos participantes: a influência dessa variável nos juízos relacionados à generosidade. Aqui, vale repetir a fala de Comte-Sponville (1995/1997), já citada anteriormente: "a generosidade nos convida, na falta de amor, a dar exatamente aos que não amamos, por necessitarem mais ou por estarmos mais bem situados para ajudá-los" (p. 110). Ora, não parece ser esse o caso da grande maioria de nossos participantes.

\section{CONSIDERAÇÕES FINAIS}

De posse dos resultados encontrados em nosso estudo, podemos afirmar que o tipo de vínculo ou a sua ausência influencia os juízos relacionados à generosidade da maior parte de nossos entrevistados. A ausência de vínculo influencia os juízos da maioria dos participantes das duas primeiras faixas etárias no que diz respeito à intensidade da ação generosa para com o outro. A inimizade, por sua vez, influencia os juízos da maior parte dos entrevistados das três idades pesquisadas.

Este trabalho apresenta apenas uma abordagem inicial ao estudo das virtudes e, em especial, da generosidade. Estudos subsequentes podem ser sugeridos. Em nossa pesquisa, algumas justificativas apresenta- 
das pelos participantes levaram-nos a pensar que a disposição para ajudar o outro expressa por eles se aproxima mais da ideia de solidariedade do que da virtude generosidade. Dessa forma, uma investigação sobre os juízos de crianças e adolescentes relacionados a esses dois valores mostra-se interessante. Destacamos, também, a importância da realização de pesquisas sobre outras virtudes como fidelidade, coragem e humildade. Acreditamos que estudos como esses contribuirão para a expansão do campo das pesquisas que se dedicam à moralidade.

Por fim, vale acrescentar que os subsídios teórico-metodológicos resultantes deste trabalho constituem o ponto de partida para a elaboração de um programa de educação moral que contemple a generosidade e considere o processo de desenvolvimento infantil. A inclusão dessa virtude nas propostas pedagógicas contemporâneas certamente enriquecerá a formação moral de crianças e adolescentes.

\section{REFERÊNCIAS}

Comte-Sponville, A. (1995). Pequeno tratado das grandes virtudes (E. Brandão, Trad.). São Paulo: Martins Fontes. (Original publicado em 1995)

Conselho Federal de Psicologia (2000). Resolução CFP n ${ }^{\circ}$ 016/2000 de 20 de dezembro de 2000. Brasília: CFP.

Conselho Nacional de Saúde (1996). Resolução no 196 de 10 de outubro de 1996. Retirado em 10 de outubro de 2009, de http://www.conselho.saude.gov.br/resolucoes/1996/Reso196.doc

Godbout, J. T. (1992). O espírito da dádiva (J. P. Cabrera, Trad.). Lisboa: Instituto Piaget.

Kohlberg, L. (1992). Psicologia del desarrollo moral. Bilbao: Desclée de Brouwer.
La Taille, Y. (2000). Para um estudo psicológico das virtudes morais. Educação e Pesquisa, 26(1), 109-121.

La Taille, Y. (2002). Vergonha, a ferida moral. Petrópolis: Vozes.

La Taille, Y. (2006a). A importância da generosidade no início da gênese da moralidade na criança. Psicologia: Reflexão $e$ Crítica, 19(1), 9-17.

La Taille, Y. (2006b). Moral e ética: Dimensões intelectuais e afetivas. Porto Alegre: Artmed.

La Taille, Y., Micelli, A., Domingues, C., Kravosac, D. B., Jamra, F. A., Fiorini, F. P., Bronstein, M., \& Neto, S. O. (1998). As virtudes morais segundo as crianças. Relatório científico FAPESP não-publicado, Instituto de Psicologia da Universidade de São Paulo.

La Taille, Y., Souza, L. S., \& Vizioli, L. (2004). Ética e educação: Uma revisão da literatura educacional de 1990 a 2003. Educação e Pesquisa, 30(1), 91-105.

Piaget, J. (s.d.). Introdução: Os problemas e os métodos. Em Piaget (Org.), A representação do mundo na criança (pp. 5-28) (R. Fiúza, Trad.). Rio de Janeiro: Record. (Original publicado em 1926)

Piaget, J. (1994). O juizo moral na criança (E. Lenardon, Trad.) ( $2^{\mathrm{a}}$ ed.). São Paulo: Summus. (Original publicado em 1932)

Piaget, J. (1996). Os procedimentos da educação moral (M. S. S. Menin, Trad.). Em L. Macedo (Org.), Cinco estudos de educação moral (pp. 2-36). São Paulo: Casa do Psicólogo. (Original publicado em 1930)

Secretaria de Educação Fundamental do Ministério da Educação e do Desporto (1997). Parâmetros curriculares nacionais. Brasília: MEC/SEF.

SPSS Inc. (1999). Statistical Package for Social Sciences Base 10.0 for Windows application guide. Chicago, IL: SPSS Inc.

Recebido: 02/07/2007

Última revisão: 08/10/2009

Aceite final: 20/10/2009

\section{Notas:}

1 Este estudo faz parte da dissertação de mestrado da primeira autora sob orientação da segunda. As autoras agradecem à Coordenação de Aperfeiçoamento de Pessoal de Nível Superior (CAPES) pelo apoio financeiro concedido.

2 Todas as vezes que citarmos a resposta ou a justificativa de um participante, apresentaremos, em seguida um nome próprio e dois números separados por ponto-e-vírgula, ambos entre parênteses. O primeiro dado diz respeito ao nome fictício do entrevistado para não comprometermos o seu anonimato. Já os números representam a idade do participante em anos e meses. Assim, “7; 10” indica 7 anos e 10 meses de idade.

\section{Sobre as autoras:}

Liana Gama do Vale: Psicóloga, Mestre em Psicologia pela Universidade Federal do Espírito Santo (UFES) e aluna de doutorado do Programa de Pós-Graduação em Psicologia Escolar e do Desenvolvimento Humano da Universidade de São Paulo (USP).

Heloisa Moulin de Alencar: Psicóloga, Doutora em Psicologia pela Universidade de São Paulo (USP) e Professora do Departamento de Psicologia Social e do Desenvolvimento e do Programa de Pós-Graduação em Psicologia da UFES.

Endereço para correspondência: Liana Gama do Vale - Rua São Clemente, 25/703 - Botafogo - 22260-001 Rio de Janeiro/RJ. Endereço eletrônco: lianadovale@yahoo.com.br. 